\title{
A high-resolution mass spectrometer to measure atmospheric ion composition
}

\author{
H. Junninen ${ }^{1}$, M. Ehn ${ }^{1}$, T. Petäjä ${ }^{1}$, L. Luosujärvi ${ }^{2}$, T. Kotiaho ${ }^{2,3}$, R. Kostiainen ${ }^{3}$, U. Rohner ${ }^{4}$, M. Gonin ${ }^{4}$, K. Fuhrer ${ }^{4}$, \\ M. Kulmala ${ }^{1}$, and D. R. Worsnop ${ }^{1,5}$ \\ ${ }^{1}$ Department of Physics, P.O. Box 64, 00014, University of Helsinki, Helsinki, Finland \\ ${ }^{2}$ Department of Chemistry, P.O. Box 55, 00014, University of Helsinki, Helsinki, Finland \\ ${ }^{3}$ Division of Pharmaceutical Chemistry, P.O. Box 56, 00014, University of Helsinki, Helsinki, Finland \\ ${ }^{4}$ Tofwerk AG, 3600 Thun, Switzerland \\ ${ }^{5}$ Aerodyne Research Inc, Billerica, MA 01821, USA
}

Received: 24 December 2009 - Published in Atmos. Meas. Tech. Discuss.: 12 February 2010

Revised: 14 July 2010 - Accepted: 18 July 2010 - Published: 17 August 2010

\begin{abstract}
In this paper we present recent achievements on developing and testing a tool to detect the composition of ambient ions in the mass/charge range up to $2000 \mathrm{Th}$. The instrument is an Atmospheric Pressure Interface Timeof-Flight Mass Spectrometer (APi-TOF, Tofwerk AG). Its mass accuracy is better than $0.002 \%$, and the mass resolving power is $3000 \mathrm{Th} / \mathrm{Th}$. In the data analysis, a new efficient Matlab based set of programs (tofTools) were developed, tested and used. The APi-TOF was tested both in laboratory conditions and applied to outdoor air sampling in Helsinki at the SMEAR III station. Transmission efficiency calibrations showed a throughput of $0.1-0.5 \%$ in the range $100-1300 \mathrm{Th}$ for positive ions, and linearity over 3 orders of magnitude in concentration was determined. In the laboratory tests the APi-TOF detected sulphuric acid-ammonia clusters in high concentration from a nebulised sample illustrating the potential of the instrument in revealing the role of sulphuric acid clusters in atmospheric new particle formation. The APi-TOF features a high enough accuracy, resolution and sensitivity for the determination of the composition of atmospheric small ions although the total concentration of those ions is typically only $400-2000 \mathrm{~cm}^{-3}$. The atmospheric ions were identified based on their exact masses, utilizing Kendrick analysis and correlograms as well as narrowing down the potential candidates based on their proton affinities as well isotopic patterns. In Helsinki during daytime the main negative ambient small ions were inorganic
\end{abstract}

Correspondence to: $\mathrm{H}$. Junninen (heikki.junninen@helsinki.fi) acids and their clusters. The positive ions were more complex, the main compounds were (poly)alkyl pyridines and amines. The APi-TOF provides a near universal interface for atmospheric pressure sampling, and this key feature will be utilized in future laboratory and field studies.

\section{Introduction}

An important phenomenon associated with the atmospheric aerosol system is the formation of new atmospheric aerosol particles. Atmospheric aerosol formation consists of a complicated set of processes that include the production of nanometer-sized clusters from gaseous vapours, the growth of these clusters to detectable sizes, and their simultaneous removal by coagulation with the pre-existing aerosol particle population (e.g., Kerminen et al., 2001; Kulmala, 2003; Kulmala and Kerminen, 2008). While aerosol formation has been observed to take place almost everywhere in the atmosphere (Kulmala et al., 2004), several gaps in our knowledge regarding this phenomenon still exist.

The recent development of physical nano condensation nuclei measurements (Kulmala et al., 2007; Mirme et al., 2007; Sipilä et al., 2008, 2009; Iida et al., 2008) has pushed the detection limit of these instruments down to the sizes where nucleation is occurring. The results show that, in addition to the more easily detectable ions, there seems to be also neutral molecules and clusters present at these sizes (Kulmala et al., 2007; Zhao et al., 2010). For sulphuric acid the charged fraction during the concentration maximum $\left(10^{7} \mathrm{~cm}^{-3}\right)$ is around $10^{-4}$.

Published by Copernicus Publications on behalf of the European Geosciences Union. 


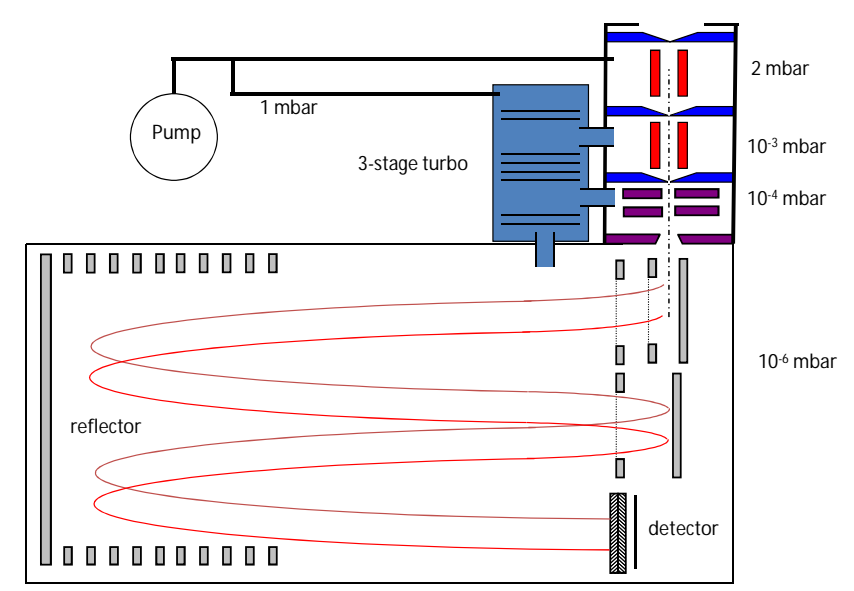

Fig. 1. Schematic of APi-TOF. First inlet chamber is pumped with separate scroll pump, other chambers are pumped with 3-stage turbo pump. Pressure drop in chambers is from 2 mbar in the first chamber to $10^{-6}$ mbar in the time-of-flight region. Red bars represent two quadruple ion guides and green bars ion lens stack to guide ions to TOF.

For resolving the participating compounds in atmospheric nucleation, chemical composition measurements need to be improved. On one hand, mass spectrometric methods can provide detailed information on the composition of atmospheric trace gases (e.g., de Gouw and Warneke, 2006; Huey, 2007) and atmospheric ions (Arnold, 1980; Eisele, 1989a, b; Tanner and Eisele, 1991; Arnold, 2008; Harrison and Tammet, 2008) and even neutral clusters (Zhao et al., 2010). On the other hand, recent development in the measurement methods of aerosol chemical composition (e.g., Jayne et al., 2000; Jimenez et al., 2002, 2009; Voisin et al., 2003; Smith et al., 2005; DeCarlo et al., 2006) has increased our capability to determine aerosol composition of smaller and smaller particles, down to $10 \mathrm{~nm}$ (Smith et al., 2008). There is still, however, a gap between the aerosol and gas phase instruments.

The aim of this study is to fill part of this gap with an atmospheric pressure interface (APi) connected to a timeof-flight mass spectrometer (TOF). We examine the performance of the APi-TOF in both laboratory and atmospheric conditions. First, we investigate the APi-TOF response to commonly used mobility standards, reporting the transmission efficiency and sensitivity. After these diagnostic tests, sulphuric acid, and sulphuric acid-ammonia cluster distributions are studied, and finally we illustrate the potential of the APi-TOF for ambient sampling and report the composition of atmospheric cluster ions at SMEAR III in Helsinki for both negative and positive polarities. The ambient data were analyzed using a newly developed software package, which is also briefly described.

\section{Instrument descriptions}

\subsection{APi-TOF}

The APi-TOF consists of a time-of-flight mass spectrometer (TOF) coupled to an atmospheric pressure interface (APi) which guides the sampled ions from atmospheric pressure to the TOF while pumping away the gas (Fig. 1). The APi is only an interface to the TOF, and should not be confused with atmospheric pressure ionisation, as the APi-TOF in our context does not by default contain any ionization method.

The APi-TOF has three differentially pumped chambers, the first two containing short segmented quadrupoles used in ion guide mode, and the third containing an ion lens assembly. The flow rate into the instrument is $\sim 0.81 \mathrm{~min}^{-1}$, regulated by a critical orifice $(300 \mu \mathrm{m})$ at the instrument inlet. The first chamber is pumped down to $\sim 2$ mbar by a scroll pump which can also be used as the backing pump for the turbo pump. The turbo pump has three stages, each pumping a different chamber as seen in Fig. 1. The final pressure in the TOF is typically $10^{-6}$ mbar.

The APi-TOF is manufactured by Tofwerk AG, Thun, Switzerland. It can be configured to measure either positive or negative ions, and can be run in either of two modes, $V$ or $W$, the letters symbolizing the flight path of the ions inside the instrument. With the shorter flight path ( $V$ mode) which was used in this study, the resolving power $(R)$ is specified to $3000 \mathrm{Th} / \mathrm{Th}$ and the mass accuracy to better than $20 \mathrm{ppm}$ $(0.002 \%)$. Resolving power is defined as $R=M / \Delta M$, where $M$ is mass/charge and $\Delta M$ is the peak width at its half maximum. The mass range of the instrument is set to be 8 $2500 \mathrm{Th}$ (corresponds to an estimated mobility diameter of $0.2-2.25 \mathrm{~nm}$ ). The TOF is the same as used in the Aerodyne aerosol mass spectrometer (DeCarlo et al., 2006) and Ionicon PTR-TOF (Jordan et al., 2009).

Data was recorded using time-to-digital converter (TDC) by co-adding spectra for $5 \mathrm{~s}$. Instrument was pulsed at frequency of $12 \mathrm{kHz}$, which leads to 60000 co-additions in $5 \mathrm{~s}$.

\subsection{Background noise and detection limit}

The APi-TOF has a very low background noise level, which makes it possible to accumulate signal over long time periods. The signal quality is limited by counting statistics, but there is a small background noise from scattered ions and electrons. The instrumental background noise is depicted in Fig. 2 panel (a), where a $60 \mathrm{~min}$ average of $15 \mathrm{~s}$ spectra has been used. The APi-TOF was sampling from ambient air with an ion filter. The noise is $0.5 \times 10^{-3} \mathrm{~cm}^{-3}$ below $100 \mathrm{Th}$ and decreases to $0.1 \times 10^{-3} \mathrm{~cm}^{-3}$ at around $m / Q$ 500 Th. Panel (b) of Fig. 2 shows the detection limit of the mass spectrometer (this does not include transmission of the ions) defined as 3 times the standard deviation of the signal during the averaging period. A power law fit was used to 


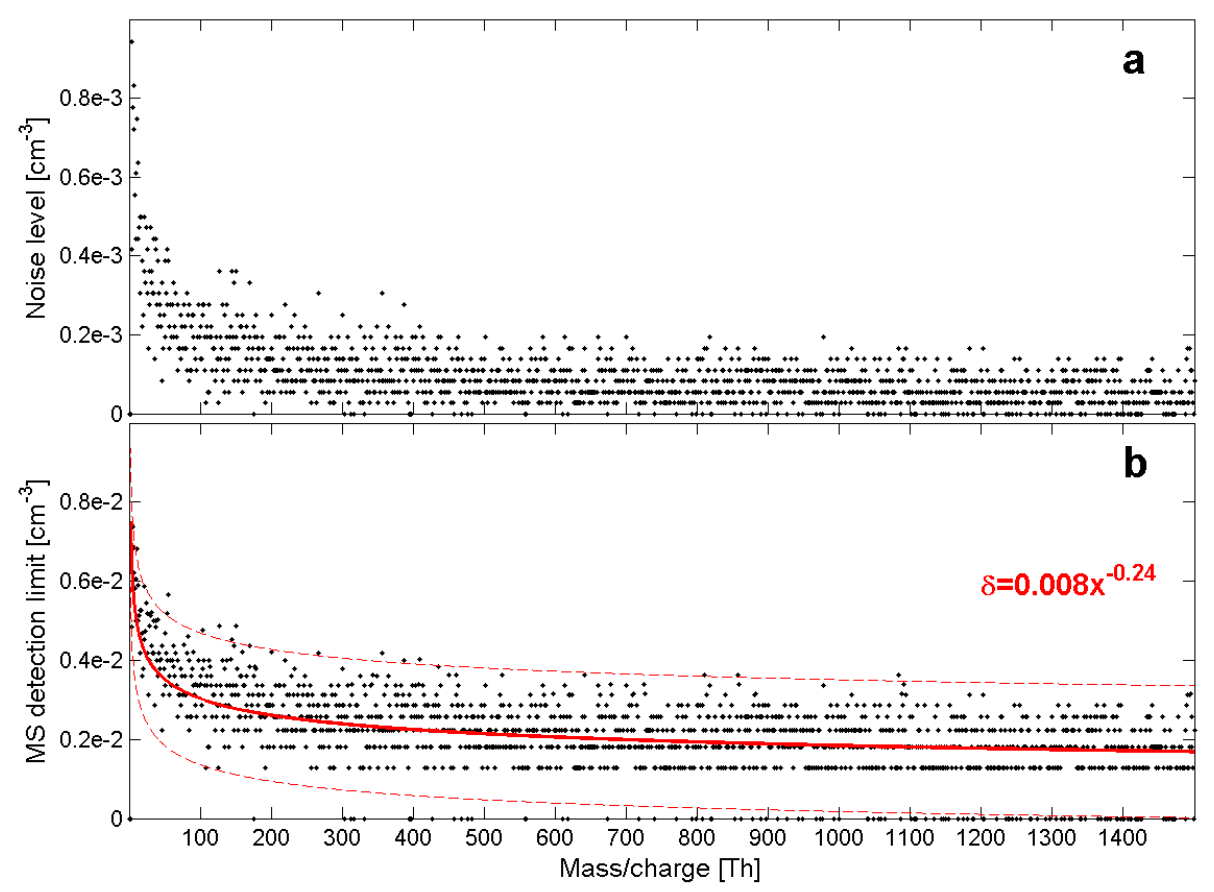

Fig. 2. The background noise and mass spectrometer detection limit of the APi-TOF based on a 60 min average of ambient sampling with an ion filter in front of the inlet. In panel (a), the black dots are 60 min average integrated signals at 1 Th resolution.In panel (b), the black dots are 3 times the standard deviation of the integrated signal, the red solid line is a power law fit to the data, and the red dashed lines are $95 \%$ confidence interval levels of the fit.

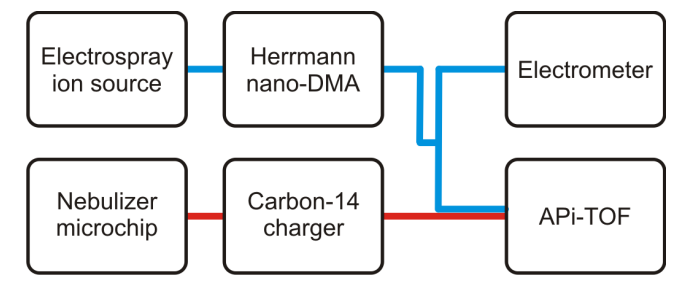

Fig. 3. Schematic laboratory setup used in this work. In the first tests (blue trace) electrosprayed mobility standards were mobility selected and passed to both an electrometer and the APi-TOF. In the other setup (red trace), the sample was produced by a microchip nebulizer and charged in a beta charger before reaching the APiTOF. For atmospheric ion measurements, the APi-TOF measured directly from the ambient.

parameterize the relation to $m / Q$. For final detection limit the ion transmission has to be taken into account and can be calculated from Eq. (1)

$D L_{\frac{m}{Q}}=\frac{c\left(\frac{m}{Q}\right)^{d}}{t r_{\frac{m}{Q}}}$

where, $D L_{m / Q}$ is the detection limit for a given $m / Q, c$ and $d$ are empirical parameters that define the detection limit of the mass spectrometer $(c=0.008, d=-0.24$ based on the
Table 1. Detection limits (DL) of APi-TOF in ions $/ \mathrm{cm}^{3}$ for a $1 \mathrm{~h}$ average with $95 \%$ confidence intervals. Settings refer to Fig. 5.

\begin{tabular}{llrrrc}
\hline Mass/charge & Transmission & DL & $-95 \%$ & $+95 \%$ & Setting \\
\hline 75 & 0.0007 & 4.6 & 4.0 & 5.2 & pos 2 \\
80 & $0.005^{\mathrm{a}}$ & 0.6 & 0.6 & 0.7 & neg $^{\mathrm{a}}$ \\
412 & 0.0037 & 0.6 & 0.5 & 0.7 & pos 2 \\
672 & 0.0043 & 0.5 & 0.4 & 0.5 & pos 2 \\
900 & 0.0046 & 0.4 & 0.3 & 0.5 & pos 2 \\
1392 & 0.00016 & 10.7 & 9.1 & 12.6 & pos 2 \\
\hline
\end{tabular}

a average of two settings

power law fit in Fig. 2) and $t r_{m / Q}$ is the transmission at the chosen $m / Q$.

In Table 1 the detection limits are calculated for selected masses using Eq. (1). It should be noted that the high DL at low and high masses can be drastically improved if the transmission can be optimized. However, for the range of good transmission the DL is well below $1 \mathrm{ion} / \mathrm{cm}^{3}$.

\subsection{Laboratory test setups}

Two different laboratory setups were used for testing the ion transmission and concentration response of the instrument. In the first setup the APi-TOF was connected in parallel with 
an electrometer, both sampling from a Herrmann nano differential mobility analyzer (HDMA, Herrmann, 2000). It takes advantage of high flow rates (sheath flow rate of up to $2000 \mathrm{~min}^{-1}$ and sample flow of $151 \mathrm{~min}^{-1}$ ) and can classify ions from 2.15 to $0.02 \mathrm{~cm}^{2} \mathrm{~V}^{-1} \mathrm{~s}^{-1}$ in electrical mobility corresponding to diameter of 0.8 to $10 \mathrm{~nm}$. The HDMA has been used previously in conjuction with the aerosol electrometer and compared with various air ion spectrometers (Asmi et al., 2009). Ions were produced by electrospraying tetra-alkyl ammonium halides, which are commonly used positive ion mobility standards (Ude and Fernandez de la Mora, 2005).

In the second set-up, the sample was produced with a heated nebulizer microchip (Saarela et al., 2007), which has previously been used in various atmospheric pressure ionization ion sources (Östman et al., 2004; Haapala et al., 2007). In this work, a syringe pump introduced a small amount of sample $\left(1-3 \mu \mathrm{min}^{-1}\right)$ to a nitrogen flow of $0.31 \mathrm{~min}^{-1}$. The nitrogen flow was heated to $300^{\circ} \mathrm{C}$ by an integrated platinum heater. The mixture was then sprayed through the nozzle of the chip producing a confined plume, which was feed directed into a Carbon-14 beta charger. To decrease losses, a bypass flow of $61 \mathrm{~min}^{-1}$ of room air was also drawn through the charger. A schematic figure of the laboratory measurements performed in this work is shown in Fig. 3, the blue trace corresponding to the first setup, and the red trace to the second.

\section{Data analysis}

\subsection{Mass calibration}

Typical data analysis of time-of-flight mass spectrometry data starts with relating the time-of-flight to the mass/charge of the ions. This relation is physically well defined, but because of instrumental factors and uncertainties in knowing the exact conditions in the ion flight region, it is common to use an empirical calibration function (Vorm and Mann, 1994; Guilhaus et al., 2000; De Carlo et al., 2006)

$M=\frac{m}{Q}=\left(\frac{t-b}{a}\right)^{2}$

where $m / Q$ is the mass/charge ratio of the ion, $t$ is the measured ion flight time, and $a$ and $b$ are instrumental parameters.

The mass calibration of a TOF is based on defining the instrumental parameters in Eq. (2) by sampling known substances over a wide range of $m / Q$, measuring ion flight times and fitting Eq. (2) to the data. In the laboratory a common practice is to calibrate the TOF before and after the measurement of an unknown sample and assume no change during the experiment. This is in general a good assumption, since the most important external factor that effects the calibration is temperature, which is reasonably constant in the laboratory. However, when measuring in a field station the tem- perature can fluctuate considerably during a day and this can change the mass calibration.

We developed a tool (tofTools) to post-process long time series of measurements utilizing an unknown sample itself and only having a known calibration occasionally. A similar approach is also used in the analysis of the Aerodyne aerosol mass spectrometer (AMS) data (De Carlo et al., 2006). However, compared to the AMS, our signals are much lower and an additional averaging prior the calibration is needed. Also, in the AMS all the spectra are very much alike and in every single AMS spectrum there is always a set of known peaks that can be used for mass calibration. The APi-TOF signal, on the other hand, does not have the virtue of having a constant ionization nor constant features in the spectra. The signal changes when the ion balance and/or composition in the atmosphere changes or when the ionization technique in front of the instrument is changed. The software cannot rely on a constant presence of background peaks that could be used for calibration.

TofTools is implemented in the MATLAB (Matlab, version 7.6, R2008 $\mathrm{a}^{1}$ ) environment and features automatic averaging, mass calibration, baseline detection, peak deconvolution and stick calculation. The software is still work in progress and is in beta-development stage. Most of the methods used in tofTools are basic data-analysis techniques and will not be discussed here. However, we find that a robust mass calibration of a partly or completely unknown spectrum is a novel feature that is not found in other software packages. Many algorithms are developed for calibration of peptide measurements with liquid chromatography TOF (e.g., Jaitly et al., 2006), or with MALDI-TOF (Wolski et al., 2005), but in these cases the second dimension from the chromatographic separation has been utilized. We only have a 1-D data.

The mass calibration of an unknown spectrum is a multistep process, where several methods are applied before the final solution is reached. The first step is to get a rough mass calibration with an accuracy of at least $0.5 \mathrm{Th}$. This is often already reached when the instrument is calibrated often enough in the field and the sampling conditions are not changed. If for some reason this is not the case, a rough mass calibration can be achieved by assuming that each peak is roughly at integer mass. The initial values (step 0 ) for this first step can be estimated $a_{0}=\sqrt{\operatorname{median}\left(\Delta t^{2}\right)}$, where $\Delta t$ is difference between adjacent peaks in time-of-flight space and $b_{0}=0$. After finding all the peaks (or peaks above some threshold) from the spectrum we find values for constants $a$ and $b$ in Eq. (2) that minimize the average distance of each peak to its integer mass $(\bar{\delta})$ as in

$\bar{\delta}=\sqrt{\frac{\sum_{i=1}^{I}\left(M_{i}-\bar{M}_{i}\right)}{I}}$,

\footnotetext{
${ }^{1}$ Matlab Inc, 3 Apple Hill Drive, Natick, MA, USA
} 
where $M$ is the integer mass, and $\bar{M}$ is the peak mass calculated by Eq. (2). The $I$ represents the number of peaks in the spectrum.

Now that the rough mass calibration is achieved, one can either search for known peaks and do a traditional mass calibration or proceed with a second step in the calibration of the unknown spectrum.

The second step in the calibrating of an unknown spectrum follows a baseline optimization. Here we assume that with the optimum values for the instrumental parameters $a$ and $b$ the average of the baseline region over the whole spectrum gives a minimum value. The baseline region is defined as a $0.4 \mathrm{Th}$ wide area between the peaks. The baseline optimization minimizes the Eq. (4)

$\beta=\sum_{i=10}^{I} \frac{\sum_{p=i+0.3}^{i+0.7} S_{p}}{L_{i}}$,

where $\beta$ is average of spectral points that belongs to baseline, $I$ is the number of integer masses, $S_{p}$ represents a spectral point at sampling number $p$, and $L$ is the number of the spectral points at integer mass $i$. Note that the number of spectral points is different for each mass, the small masses are sampled at a higher rate due to the relation in Eq. (2).

After this step, unit mass resolution time series are calculated and can be analysed and used for peak identification. Once enough peaks are positively identified, these masses can be added to a mass table which is subsequently used to recalibrate the current and future similar spectra with a high mass accuracy.

Table 2 demonstrates the performance of each calibration step on ambient spectrum of positive ions, where series of pyridine peaks have been used for testing $(80.0495,94.0651,108.0808,122.0964,136.1121$, $150.1277,164.1434,178.1590)$. Already the step 1 is sufficient for unit mass resolution sticks (accuracy $666 \mathrm{ppm}$, that translates to an error in $100 \mathrm{Th}$ of $0.067 \mathrm{Th}$ ) and the final step 2 improves the calibration of unknown sample even further. For the peak at $100 \mathrm{Th}$ the final calibration error is $0.007 \mathrm{Th}$, that is only 2 times higher than with the manual calibration. Still, for highest mass accuracy the traditional manual calibration with known peaks should be used.

\subsection{Peak identification}

The APi-TOF by default does not provide any chemical or physical separation prior to sampling as is often done in GCMS, LC-MS or MS-MS systems. However, due to the high sensitivity, accuracy and mass and time resolution of the APiTOF, many techniques can be used to determine the elemental and even molecular composition of the peaks with a high degree of certainty. The certainty decreases for larger $m / Q$. The main techniques for peak identification used are; defining the exact mass and performing Kendrick analysis, studying isotopic patterns, plotting correlograms of time series, proton affinity considerations and applying the nitrogen rule.

\subsubsection{Exact mass and Kendrick analysis}

High resolution mass spectrometry does not only give a possibility to separate closely located peaks, but also gives information on the composition of the substrate. The position of a peak compared to its integer mass is called a mass defect and it is dependent on the elemental composition of the molecule. When the instrument is well calibrated, the accuracy is less than $20 \mathrm{ppm}$, leaving few options at masses below $200 \mathrm{Th}$. Table 3 lists exact masses and the mass defects of some common elements and some selected organic molecules.

Members of hydrocarbon homologous series differ from each other by a mass of $\mathrm{CH}_{2}(14.01565 \mathrm{Da})$. Thus, it is possible to recognise patterns of compounds belonging to the same family by finding a series of peaks differing by $14.01565 \mathrm{Th}$. It simplifies the interpretation of a complex organic mass spectrum by expressing the mass of hydrocarbon molecules in Kendrick units (where $m\left({ }^{12} \mathrm{CH}_{2}\right)=14 \mathrm{Ke}$ ) instead of Dalton (where $m\left({ }^{12} \mathrm{C}\right)=12 \mathrm{Da}$ ) (Kendrick, 1963). In Kendrick units all the members of the homologous series have the same Kendrick mass defect (see Table 3) (Hughey et al., 2001; Smith et al., 2009). Kendrick (1963) defined the Kendrick Mass Defect as Nominal Kendrick Mass Kendrick Mass, but this expression produces negative values for masses that are higher than their integer masses. In this work we have chosen to define the Kendrick Mass Defect as Kendrick Mass - Nominal Kendrick Mass as this is more intuitive when the mass defect and Kendrick Mass Defect behave similarly.

Based on the difference of hydrogen and carbon in heteroatom organic molecules we can classify each molecule $\mathrm{C}_{\mathrm{c}} \mathrm{H}_{\mathrm{h}} \mathrm{N}_{\mathrm{n}} \mathrm{O}_{\mathrm{o}} \mathrm{S}_{\mathrm{S}} \mathrm{P}_{\mathrm{p}}$ with an integer number $Z$

$Z=h-2 c$,

where $h$ is the number of hydrogen and $c$ is the number of carbon atoms in the molecule. Hence $Z$ reflects the number of rings and double bonds in the molecule.

For example a protonated pyridine, $\mathrm{C}_{5} \mathrm{H}_{6} \mathrm{~N}^{+}$has $Z=6-$ $10=-4$ and is denoted as a type $-4 \mathrm{~N}$ and for an aminophenol $\mathrm{C}_{6} \mathrm{H}_{8} \mathrm{NO}^{+}, Z=8-12=-4$ and is denoted as type $-4 \mathrm{NO}$ (Hughey et al., 2001).

If we plot the Kendrick mass defects against the Kendrick nominal masses, all the substances that belong to the same homologous series and to the same compound type align on the same horizontal line. The compound types have different Kendrick mass defects and are separated by $0.0134 \mathrm{Ke}$ (the Kendrick mass defect of 2 hydrogen atoms). This is called a Kendrick diagram. Additionally, when using a known mass accuracy for the instrument we can automatically search for substances that belong to a specific family by searching for the peaks that have a nominal Kendrick mass matching the series, and the Kendrick mass defect is within plus or minus the mass accuracy. Highlighting the discovered peaks greatly 
Table 2. Mass accuracy (ppm) of each calibration step. For clarity also the error (Th) at $100 \mathrm{Th}$ and assumption made at each step are reported.

\begin{tabular}{crcl}
\hline Calibration step & Accuracy & Error at 100 Th & Assumption \\
\hline Step 0 & 2600.3 & 0.260 & Majority of peaks 1 Th apart \\
Step 1 & 665.9 & 0.067 & Peaks at integer mass $(<300 \mathrm{Th})$ \\
Step 2 & 68.1 & 0.007 & Baseline minimization $(<800 \mathrm{Th})$ \\
Manual & 20.2 & 0.002 & Known calibration peaks \\
\hline
\end{tabular}

Table 3. Exact masses, mass defects, Kendrick mass defects and compound types for selected elements and molecules.

\begin{tabular}{lcccc}
\hline Name, elemental composition & Exact mass & Mass defect & $\begin{array}{l}\text { Kendrick mass } \\
\text { defect }\end{array}$ & $\begin{array}{c}\text { Compound } \\
\text { type }\end{array}$ \\
\hline Hydrogen, $\mathrm{H}$ & 1.0078250 & 0.007825 & 0.006700 & $\mathrm{ND}$ \\
Carbon, $\mathrm{C}$ & 12.000000 & 0 & -0.013399 & $\mathrm{ND}$ \\
Nitrogen, $\mathrm{N}$ & 14.003074 & 0.003074 & -0.012562 & $\mathrm{ND}$ \\
Oxygen, $\mathrm{O}$ & 15.994915 & -0.005085 & -0.022945 & $\mathrm{ND}$ \\
Sulphur, $\mathrm{S}$ & 31.972072 & -0.027929 & -0.063628 & $\mathrm{ND}$ \\
Iodine, $\mathrm{I}$ & 126.90447 & -0.095523 & -0.237226 & $\mathrm{ND}$ \\
$\mathrm{CH}_{2}$ & 14.01565 & 0.01565 & 0 & 0 \\
Pyridine, $\mathrm{C}_{5} \mathrm{H}_{5} \mathrm{~N}$ & 79.042199 & 0.042199 & -0.046060 & $-5 \mathrm{~N}$ \\
Methyl-pyridine, $\mathrm{C}_{6} \mathrm{H}_{7} \mathrm{~N}$ & 93.057849 & 0.057849 & -0.046060 & $-5 \mathrm{~N}$ \\
Dimethyl-pyridine, $\mathrm{C}_{7} \mathrm{H}_{9} \mathrm{~N}$ & 107.07350 & 0.073499 & -0.046060 & $-5 \mathrm{~N}$ \\
Quinoline, $\mathrm{C}_{9} \mathrm{H}_{7} \mathrm{~N}$ & 129.05785 & 0.057849 & -0.086258 & $-11 \mathrm{~N}$ \\
Methyl-quinoline, $\mathrm{C}_{10} \mathrm{H}_{9} \mathrm{~N}$ & 143.07350 & 0.073499 & -0.086258 & $-11 \mathrm{~N}$ \\
Dimethyl-quinoline, $\mathrm{C}_{11} \mathrm{H}_{11} \mathrm{~N}$ & 157.08915 & 0.089149 & -0.086258 & $-11 \mathrm{~N}$ \\
\hline
\end{tabular}

ND - not defined

aids in identifying the peaks in the mass spectrum. An example of such an analysis is shown in Sect. 4.5.

Before the data is plotted on the Kendrick diagram, one has to determine the exact $m / Q$ of the peaks in the spectrum. In tofTools we have implemented a peak fitting routine where Gaussian distributions are used. Compared to standard peak fitting procedures some changes have been implemented: 1) weighting is applied to the negative residuals (the over fitted data points). This modification makes the fitting more robust against skewed peaks, and gives a better estimation of the exact peak location (exact $m / Q$ ). 2) Peak area is not fitted, but is calculated by solving $n$ linear equations ( $n=$ number of overlaying peaks) using matrix algebra (Hussein et al., 2005). This speeds up the fitting algorithm considerably, particularly when multiple overlaying peaks are fitted. 3) The width of the fitted peaks is constrained to a single parameter which is scaled by a linear function of the $m / Q$ ratio (De Carlo et al., 2006). The dependency of the peak width on the $m / Q$ is evaluated from a set of peaks that do not have interefering peaks at the same nominal mass. Here we have used ammonia, isopropanol, butanol, acetone, pinene and two siloxane peaks (462.123 Th and 536.142 Th). All compounds except ammonia were separately added to the sam- ple. The siloxanes are contaminants from conductive tubing and are very easily ionized with a radioactive charger. The width to mass relation is depicted in Fig. 4. The peak width from the fitting without constraining the width is also plotted in the same figure. After $180 \mathrm{Th}$ we can see how the unconstrained peak fits generate artificially too wide peaks. This makes the determination of the exact mass difficult, since the number of possible molecules at each peak is higher and the peak is actually a combination of multiple overlaid peaks. The determination of the exact composition becomes more challenging at a higher $m / Q$ also due to the greater number of permutations of elements in a molecule.

At the final stage in the peak fitting routine we minimize a weighted root mean square error of fitted Gaussians compared to measured data with a Matlab built-in optimization function based on the Levenberg-Marquardt algorithm (Marquardt, 1963).

\subsubsection{Isotopic patterns}

Some elements have more than one stable isotope with fairly high abundance, such as sulphur with the isotopes ${ }^{32} \mathrm{~S},{ }^{33} \mathrm{~S}$ and ${ }^{34} \mathrm{~S}$, with abundances of $95.02 \%, 0.75 \%$ and $4.21 \%$, respectively. This can often be used to rule out sulphur when 


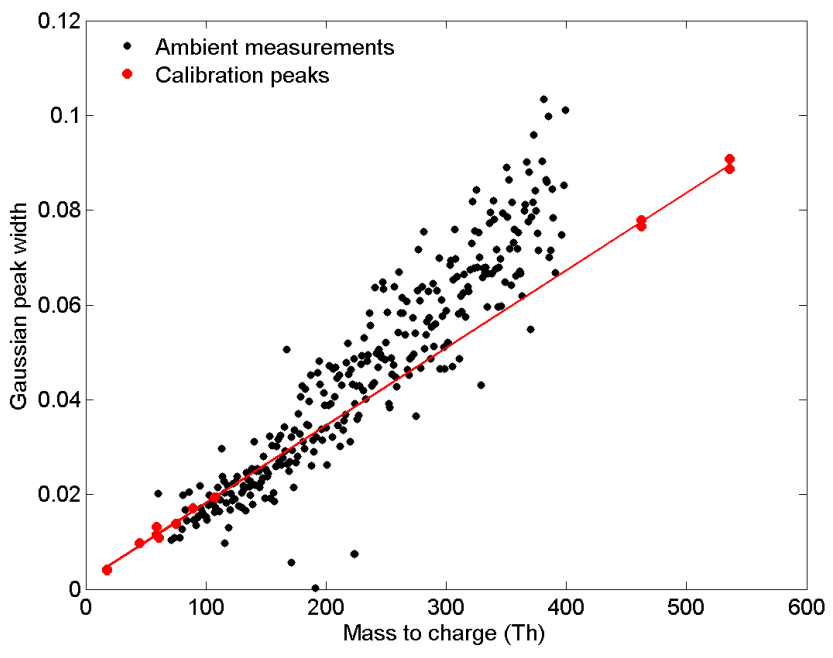

Fig. 4. Peak width dependency on $m / Q$. Black dots are peaks from ambient measurement and red dots are known pure substance peaks, all are fitted without constraining the peak width. Deviation of ambient measurements form the red line (linear fit to calibration peaks) indicates the presence of multiple overlying peaks at $m / Q>$ $180 \mathrm{Th}$.

determining the molecular formula for a peak. Other elements that have high abundance stable isotopes and are relevant in the current study are silicon (a common contaminant from conductive tubing) and bromide (calibration substance). Examples of the bromide and sulphur isopic distributions are present in Sects. 4.2 and 4.4, respectively.

\subsubsection{Correlation diagrams of the time series}

Molecules with the same source have similar time trends, and this becomes a very helpful tool once a long time series is collected. This proved especially useful in identifying the peaks of molecular clusters, with correlation coefficients between monomer/dimer/trimer peaks being very high. An example about the usage is presented in Sect. 4.5.

\subsubsection{Other criteria}

All of the identified peaks in the ambient negative and positive ion spectra were found to be charged through proton transfer, as shown in Sect. 4, which gives two more tools for the identification: a) proton affinity. The positive ion spectrum will be dominated by the compounds with the highest proton affinities, such as amines, charged by uptake of $\mathrm{H}^{+}$. The negative ion spectrum, on the other hand, will be dominated by the anions with the lowest proton affinities, mainly inorganic and organic acids. b) The nitrogen rule: if a substance is detected at an even integer mass, it will contain an odd number of $\mathrm{N}$ if ionization involved a proton transfer.

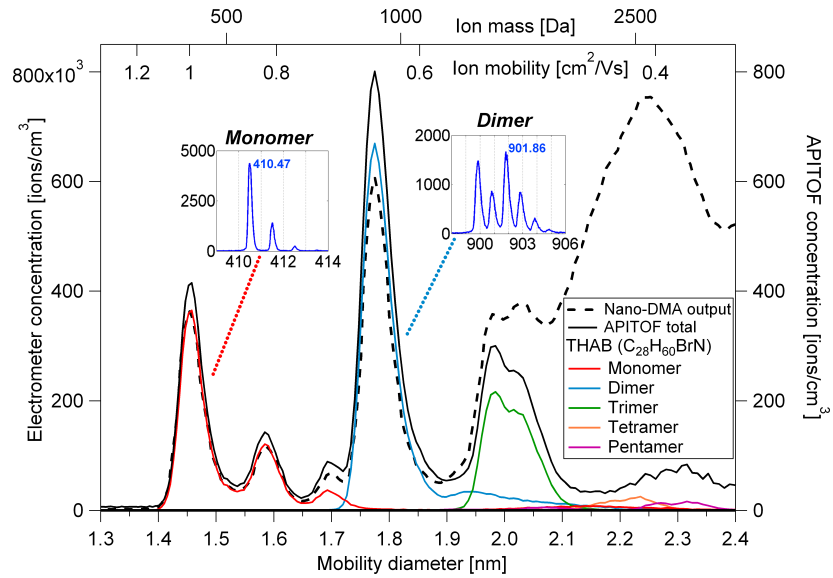

Fig. 5. An electrometer sampled in parallel with the APi-TOF behind a nano-DMA sampling electrosprayed tetra-heptyl ammonium bromide (THAB). The DMA scanned the over the size range in the figure, and the total ion count exiting the DMA is plotted as a black dashed line, with the total APi-TOF count plotted as the solid black line. Lines of other colours are the signals in the APi-TOF from different clusters of THAB. The monomer and dimer isotopic distributions are also shown. The factor of 1000 difference is due to losses inside the APi-TOF. At $m / Q>1000$ Th the transmission falls off even more. For comparison, the horizontal scale is depicted in both mass, mobility, and mobility diameter.

\section{Results}

\subsection{Comparison with ion mobility standards}

Tetra-heptyl ammonium bromide (THAB) was electrosprayed into a Herrmann DMA, which scanned the mobility range from 0.3 to $1.3 \mathrm{~cm}^{2} \mathrm{~V}^{-1} \mathrm{~s}^{-1}$, and the output was measured by an electrometer and the APi-TOF. The results are depicted in Fig. 5. The electrometer counts all the ions coming out of the HDMA, and this concentration is plotted as the black dashed line in Fig. 5. From previous ion mobility studies (Ude and Fernandez de la Mora, 2005) we know that the peak at mobility diameter $1.47 \mathrm{~nm}$ corresponds to the THAB monomer, and the peak at $1.78 \mathrm{~nm}$ to the dimer. This was also clearly verified by the APi-TOF.

The horizontal axis in Fig. 5 shows the mass, mobility, and mobility diameter scales. The three different axes are not universally interchangeable, but they are plotted here for reference to show rough relations between three very commonly used quantities. The mass to mobility relationship can be constructed (Ku and Fernandez de la Mora, 2009) since the composition of the THAB clusters are known, and the exact masses can be calculated (and are also measured by the APi-TOF) and the mobility of the clusters has been measured by (Ude and Fernandez de la Mora, 2005). In the same study also the mobility diameter has been calculated up to the THAB pentamer, and this can be used to construct the mass to mobility diameter relationship. 


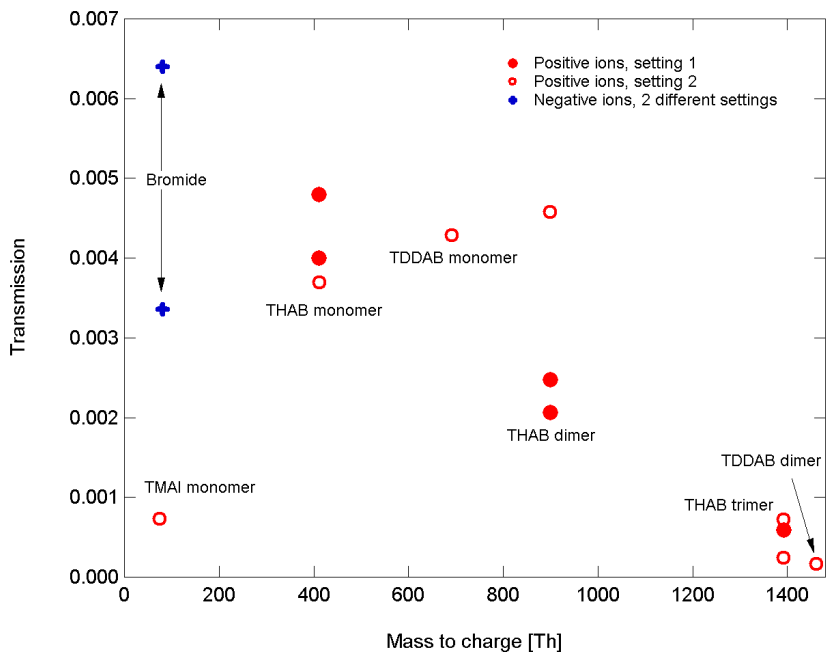

Fig. 6. Ion transmission efficiency for APi-TOF using electrosprayed mobility standards and nano-DMA for mobility separation. TMAI - tetramethyl ammonium iodide, THAB - tetra-heptyl ammonium bromide, TDDAB - tetradodecyl ammonium bromide. Transmission is the fraction of ions reaching the detector out of the ions at inlet.

The total ion count seen by the APi-TOF is depicted by the solid black line. Electrometer counts are plotted on the left axis, and APi-TOF counts on the right. The other lines correspond to the ion counts related to the different THAB peaks. As an example, the most abundant isotope of the tetraheptyl ammonium cation $\left(\mathrm{THA}^{+}\right.$, in the following denoted as "monomer") has a mass of $410.47 \mathrm{Da}$. The measured isotopic pattern can be found in the monomer inset figure, and the shape is mainly due to the ${ }^{13} \mathrm{C}$ isotope. Summing up the total signal in the three major isotopes, yields the total monomer signal and this corresponds to the red line in Fig. 5. The dimer consists of a neutral THAB clustered with $\mathrm{THA}^{+}$, yielding a maximum mono-isotopic mass of $901.86 \mathrm{Da}$. Bromide has two isotopes of roughly equal abundance at masses 79 and $81 \mathrm{Da}$, and thus the isotopic pattern detected by the APi-TOF is very distinctive as can be seen in the dimer inset figure. Again, summing the signal in all of these peaks yields the total dimer signal, resulting in the light blue line in Fig. 5.

Since we are able to detect THAB clusters up to pentamers, no considerable fragmentation of the those clusters happened inside the APi-TOF. If this would have been the case, and pentamers and higher clusters would fall apart inside the APi-TOF, we should instead detect the smaller fragments which retained the charge, but this was not the case. This is, however, probably the case with the peak at $1.6 \mathrm{~nm}$ which shows up in the APi-TOF as pure monomer although it had a larger size when passing through the HDMA. This implies that it had been clustered with some impurity compound, which was lost before entering the extraction region in the TOF. Losses in the transfer lines were not accounted for, but flow rates were kept high, at $81 \mathrm{~min}^{-1}$ and the lines to both of the instruments were of equal length yielding similar losses.

\subsection{Transmission}

Based on Fig. 5, the APi-TOF signal is roughly a factor of 1000 smaller than the electrometer for the monomer and dimer, and this gives an estimate of the transmission of ions from the critical orifice to the detector inside the APi-TOF. For the trimer the transmission has decreased slightly, and for the tetra- and pentamers the transmission has decreased considerably. It should be noted that the electrometer output also becomes more of a continuum after the trimer, possibly due to fragmentation of larger clusters inside the HDMA, thus exact transmission estimates at high masses are somewhat uncertain with this setup.

As the losses inside the APi-TOF are $m / Q$ dependent, measurements were conducted to map out the transmission curve for the instrument. By transmission, we here mean the fraction of the ions reaching the detector out of the ions reaching the inlet. Thus, it takes into account losses in the inlet, in both of the quadrupoles and in the ion guides, and also the ions passing through the extraction region of the TOF in between extractions (duty cycle).

One way to measure the transmission is to select a monodisperse output from the HDMA and compare the counts in the APi-TOF to those of the electrometer. This was done at several occasions for the THAB monomer-trimer, and with some other tetra-alkyl ammonium halides. The results are shown in Fig. 6. Most of the data is measured in a positive ion mode, as the positive ion mobility standards are much more readily available. Transmission for the smallest mobility standards TMAI at $74 \mathrm{Th}$ and bromide at $80 \mathrm{Th}$ (summed signal of isotopes ${ }^{79} \mathrm{Br}$ and ${ }^{81} \mathrm{Br}$ ) was ranging from 0.07 to $0.64 \%$. The big difference from measurement to measurement is not due to uncertainty in the sampling, but it is the effect of different voltage settings in the APi. Similarly strong dependency on voltage settings was observed on all measured mass ranges, although the difference was the highest with the smallest mass/charge ratio. For THAB monomer (sum over isotopes $410-413 \mathrm{Th}$ ) the transmission was from $0.3 \%$ to $0.6 \%$, for THAB dimer (sum over isotopes 897 $902 \mathrm{Th}$ ) the transmission was ranging from $0.2 \%$ to $0.5 \%$. The heaviest ion tested (THAB trimer, sum over isotopes $1388-1396 \mathrm{Th}$ ) had the transmission of $0.02-0.06 \%$. The final transmission is strongly dependent on the voltage settings in the APi part.

\subsection{Concentration response}

The response to the changes in concentration seemed to be fairly linear based on the THAB experiments in Sect. 4.1, and this was an assumption we needed to make in order to calculates $m / Q$ dependent transmissions. 
In order to confirm the linearity, we made an additional experiment with a setup that allows a quantitative control of the number of ions we produce. We used a nebulizer microchip to produce known concentrations of three organic aromatic compounds (verapamil, propanolol and aciridine) that have high proton affinities. We used a ${ }^{14} \mathrm{C}$ beta source to charge the sample. When looking at the positive ions in the bi-polar source, a cascade of collisions transfer the charge (proton) to compounds with the highest proton affinities, which were in this case our sample.

The response was found to be very close to linear over at least 3 orders of magnitude (Fig. 7) for all three compounds. The ion count per second of the APi-TOF is plotted on the $y$-axis and the amount of molecules produced by the nebulizer chip ranging from $1 \times 10^{6}$ to $1 \times 10^{10}$ molec s$^{-1}$ (corresponds to nebulised liquid sample concentration $3 \times 10^{-2}$ to $3 \times 10^{2} \mathrm{nM}$ ) on the $\mathrm{x}$-axis. In the low concentration end, we reached the concentration limit that could be detected with the set-up, which explains the deviation from the linear curve. In the high concentration side, the deviation is most likely due to the charging mechanism, as this comparison assumes that the charged fraction of the compounds is constant. However, the beta charger will always produce a limited amount of charges, and these will start to recombine immediately. Thus, at very high concentrations we expect the amount of ions able to charge the sample to begin to be exhausted and the sample can no longer be ionized to the same extent.

\subsection{Sulphuric acid tests}

To probe the APi-TOF response to atmospherically relevant test compounds, sulphuric acid $\left(\mathrm{H}_{2} \mathrm{SO}_{4}\right)$ was nebulized with a microchip, and sampled in a similar way as the compounds in Sect. 4.3. The high concentration of $\mathrm{H}_{2} \mathrm{SO}_{4}$ facilitated cluster formation, and the dominant peaks were $\mathrm{H}_{2} \mathrm{SO}_{4}$ monomer, dimer, trimer and tetramer $\left(\mathrm{HSO}_{4}^{-}\right.$, $\left.\mathrm{H}_{2} \mathrm{SO}_{4} \cdot \mathrm{HSO}_{4}^{-},\left(\mathrm{H}_{2} \mathrm{SO}_{4}\right)_{2} \cdot \mathrm{HSO}_{4}^{-},\left(\mathrm{H}_{2} \mathrm{SO}_{4}\right)_{3} \cdot \mathrm{HSO}_{4}^{-}\right)$. There was also a very small signal at the $\mathrm{H}_{2} \mathrm{SO}_{4}$ pentamer, but starting from the tetramer, the pattern at larger masses was dominated by clusters of 4 or more $\mathrm{H}_{2} \mathrm{SO}_{4}$ together with ammonia, $\mathrm{NH}_{3}$ (Fig. 8). The upper panel shows the signal in the $m / Q$ range $75-400 \mathrm{Th}$, and it is dominated by the $\mathrm{H}_{2} \mathrm{SO}_{4}$ clusters mentioned above, at integer $m / Q 97,195,293$ and 391. Additionally there are large peaks at 89 (oxalic acid, HOOC-COO ${ }^{-}$, lactic acid, $\left.\mathrm{CH}_{3} \mathrm{CH}(\mathrm{OH}) \mathrm{COO}^{-}\right)$and 187 (oxalic acid sulphuric acid cluster, $\mathrm{HOOH}-\mathrm{COOH} \cdot \mathrm{HSO}_{4}^{-}$). The first contains two different species, as seen in the inset figure in the top panel of Fig. 8, and is dominated by oxalic acid (HOOC-COO${ }^{-}$), with a shoulder of lactic acid $\left(\mathrm{CH}_{3} \mathrm{CH}(\mathrm{OH}) \mathrm{COO}^{-}\right)$, whereas the latter is a cluster of oxalic acid with sulphuric acid. The bottom panel depicts the $m / Q$ range $400-1000 \mathrm{Th}$, with signals above $m / Q 700$ multiplied by a factor of 10 . All the large signals correspond to $\left(\mathrm{H}_{2} \mathrm{SO}_{4}\right)_{\mathrm{m}}\left(\mathrm{NH}_{3}\right)_{\mathrm{n}} \mathrm{HSO}_{4}^{-}$clusters, with a notable exception

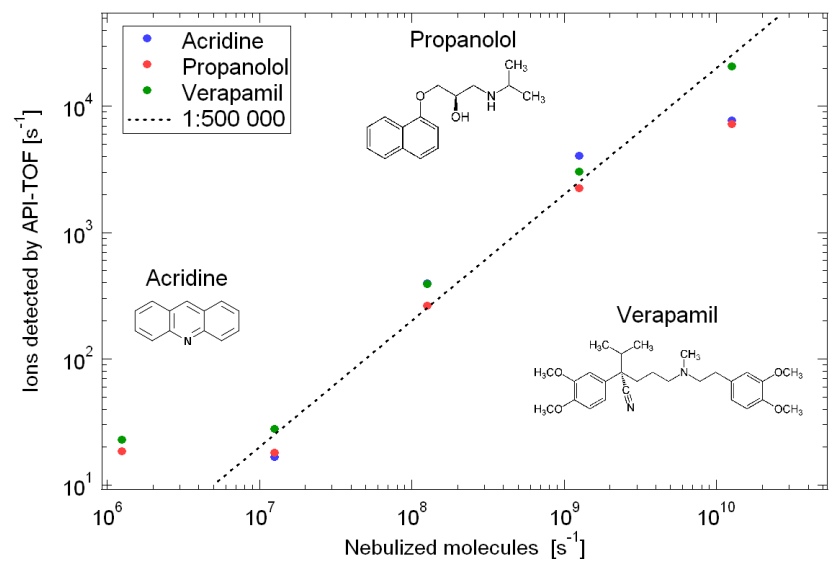

Fig. 7. Varying concentrations of three different organic compounds were nebulized with a microchip, passed through a beta charger, and measured by the APi-TOF. The concentration response was linear over the three orders of magnitude. The 1:500 000 line is mainly explained by the charging efficiency of the molecules, and the transmission of the APi-TOF, both probably around $0.1-1 \%$.

at integer $m / Q 451$ which is a cluster of the $\mathrm{H}_{2} \mathrm{SO}_{4}$ tetramer and urea $\left(\mathrm{CO}\left(\mathrm{NH}_{2}\right)_{2}\right.$, carbonyldiamine). Urea, ammonia and lactic acid are all common constituents of sweat (Robinson, 1954), and are also detected in vapours of human skin by on-line electrospray ionization mass spectrometry (MartinezLozano and Fernandez de la Mora, 2009), where the set-up used was a very similar to ours. It is therefore not surprising to find these compounds in our laboratory air, however source for oxalic acid is not clear.

For a better overview, the abundance of all the detected $\left(\mathrm{H}_{2} \mathrm{SO}_{4}\right)_{\mathrm{m}}\left(\mathrm{NH}_{3}\right)_{\mathrm{n}} \mathrm{HSO}_{4}^{-}$clusters, where $m=0-9$ and $n=0-$ 4, is also plotted in Fig. 9. The color scale is logarithmic, and scaled to the dimer concentration. The numbers in white inside each box shows the integer $m / Q$ at which the cluster was detected. We only detect ammonia in clusters with 4 or more $\mathrm{H}_{2} \mathrm{SO}_{4}$, which is in fairly good agreement with (Ortega, 2009) who calculated that the addition of ammonia to a sulphuric acid cluster becomes more favourable the more $\mathrm{H}_{2} \mathrm{SO}_{4}$ molecules already in the cluster. Also (Hanson and Eisele, 2002) measured $\left(\mathrm{H}_{2} \mathrm{SO}_{4}\right)_{\mathrm{m}}\left(\mathrm{NH}_{3}\right)_{\mathrm{n}} \mathrm{HSO}_{4}^{-}$negative ion clusters and found that ammonia was abundant in clusters starting from the $\mathrm{H}_{2} \mathrm{SO}_{4}$ tetramer.

It should be noted that the charging inside the beta source is likely to involve such high energy collisions that almost all the clusters will break apart, and the detected clusters are formed after exiting the charging area. The absolute concentration of $\mathrm{H}_{2} \mathrm{SO}_{4}$ in this experiment could not be calculated, but it was probably several orders of magnitude higher than typical daytime ambient concentrations. Nevertheless, we have shown that the APi-TOF can detect these $\left(\mathrm{H}_{2} \mathrm{SO}_{4}\right)_{\mathrm{m}}\left(\mathrm{NH}_{3}\right)_{\mathrm{n}} \mathrm{HSO}_{4}^{-}$clusters, and this may prove to be very relevant for atmospheric nucleation and new particle formation. 


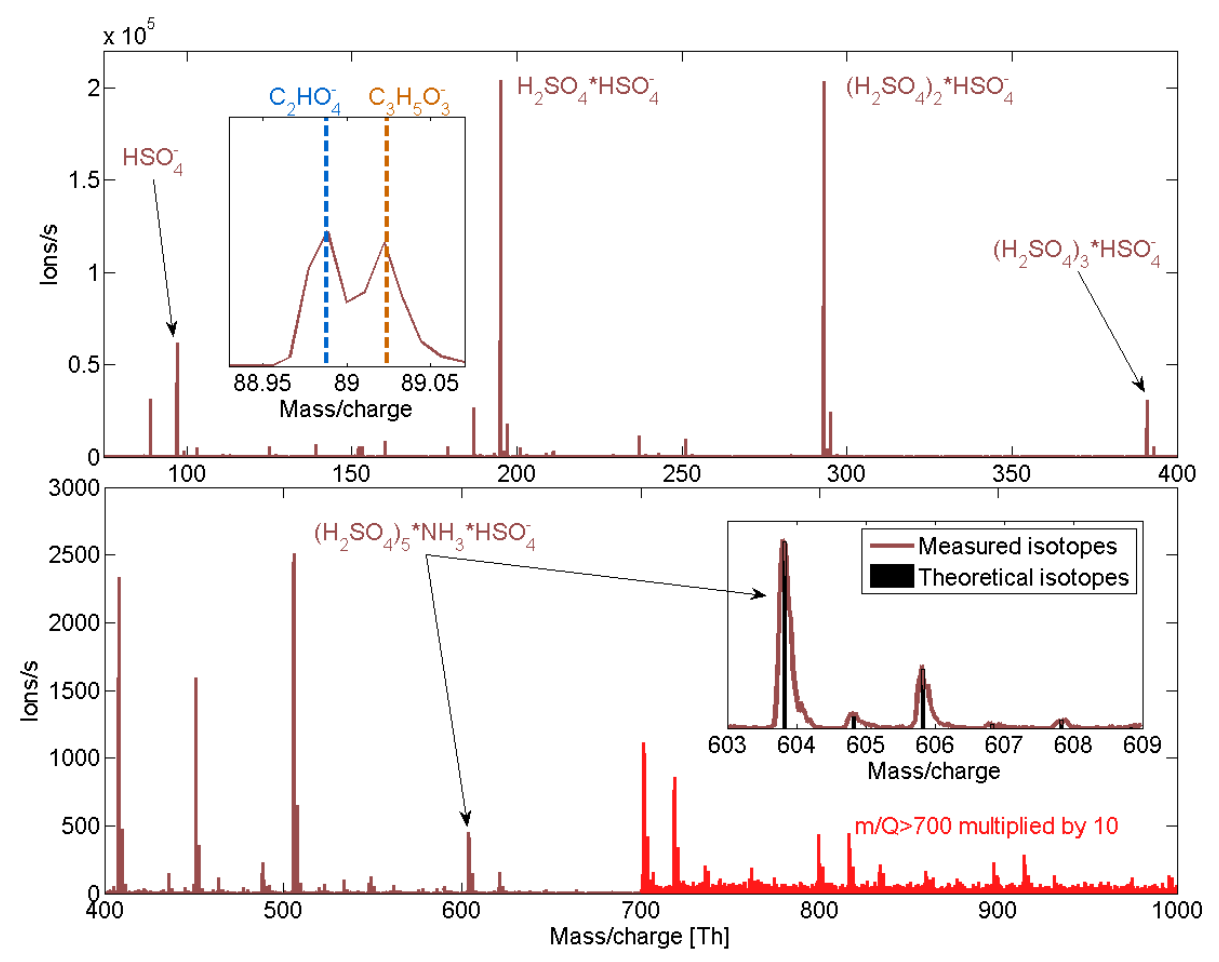

Fig. 8. Sulphuric acid was nebulized with a microchip and mixed with laboratory air before passing through a beta charger. The dominant peaks in the $m / Q$ range below $400 \mathrm{Th}$ (upper panel) are sulphuric acid monomer-tetramer, followed by a peak at integer $m / Q 89 \mathrm{Th}$ which is most likely a mix of oxalic and lactic acid, as seen in the inset plot. The $m / Q$ range above $400 \mathrm{Th}$ is dominated by $\left(\mathrm{H}_{2} \mathrm{SO}_{4}\right)_{\mathrm{m}}\left(\mathrm{NH}_{3}\right)_{\mathrm{n}} \mathrm{HSO}_{4}^{-}$ clusters. The identification was made based on the exact $m / Q$, and verified by the matching isotopic distributions, as can be seen in the inset showing the measured and theoretical isotopes of six $\mathrm{H}_{2} \mathrm{SO}_{4}$ with $\mathrm{NH}_{3}$.

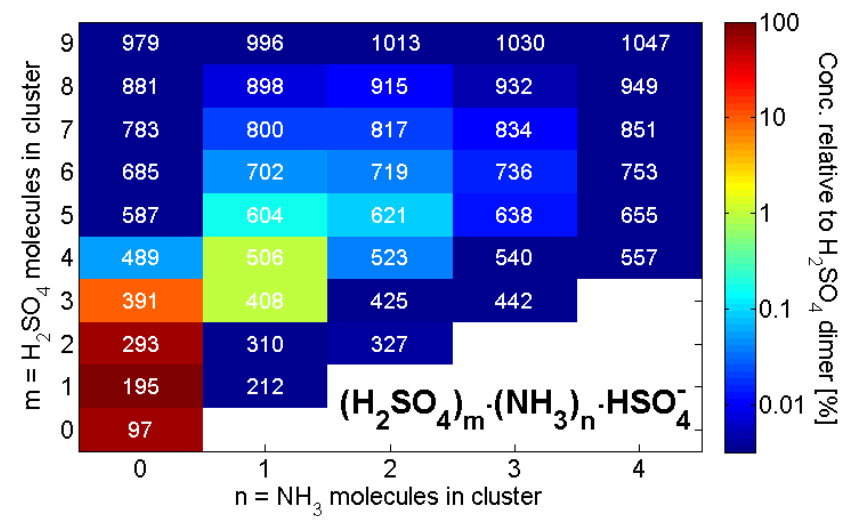

Fig. 9. Relative abundances of observed $\left(\mathrm{H}_{2} \mathrm{SO}_{4}\right)_{\mathrm{m}}\left(\mathrm{NH}_{3}\right)_{\mathrm{n}} \mathrm{HSO}_{4}^{-}$ clusters. The white numbers correspond to the integer masses at which the clusters were detected. Concentrations are scaled to the dimer ion at integer $m / Q 195$.

\subsection{Ambient data}

The concentration of atmospheric ions is usually on the order of 400-2000 ions $\mathrm{cm}^{-3}$ per polarity (Hirsikko et al., 2004). To demonstrate the sensitivity of the APi-TOF, we present ambient air ion data collected at the SMEAR III station in Helsinki, Finland (Järvi et al., 2009). The ambient ions are a subset of the gas phase molecules and clusters which have obtained a charge, usually by donating or receiving a proton. Therefore the ions do not accurately represent the whole bulk gas phase composition of the air. The positive ion spectrum will be dominated by the molecules with the highest proton affinities, whereas the negative ion spectrum will be dominated by the anions that have the strongest gas phase acidity. The ambient data was analysed using tofTools as described above.

Day time spectra are presented in Fig. 10, for both negative (Fig. 10a) and positive (Fig. 10b) ions. The data is averaged over $6 \mathrm{~h}$. The negative ion spectrum is dominated by different inorganic acids, mainly nitric (blue), sulphuric (red) and iodic acid (purple), and their dimers and water clusters. Clusters between the different acids are also visible (brown). While the nitric and sulphuric acid clusters are expected and have been detected before in the ambient negative ion spectrum (Eisele, 1989a; Zhao et al., 2010), iodine compounds have not been previously reported. Figure 11 shows clear correlation between all iodine containing peaks including clusters with sulphuric and nitric acid. This shows the power of using correlograms in ambient data 

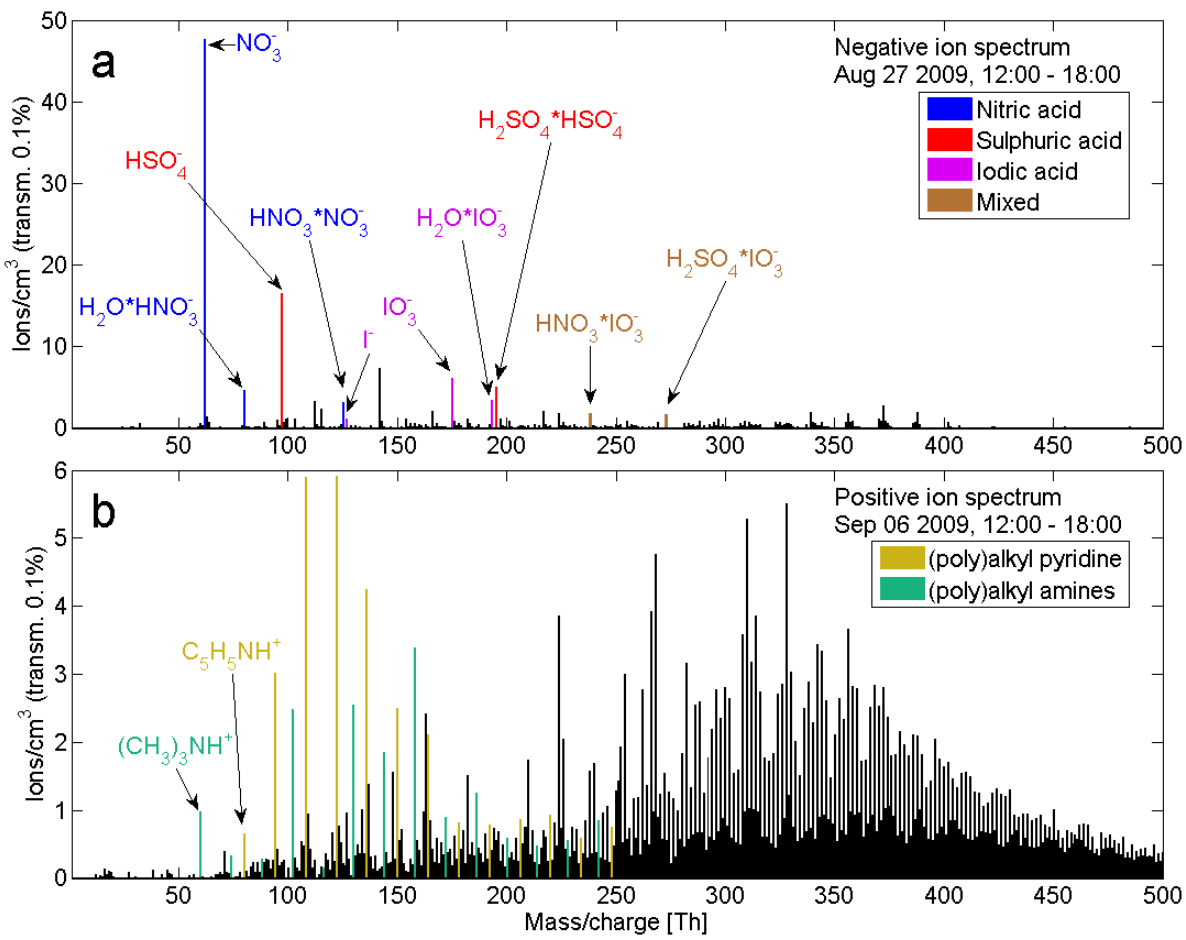

Fig. 10. Example ambient ion mass spectra. Top panel (a) shows negative ions and bottom panel (b) shows positive ions. The negative ion spectrum is dominated by strong acids and is much easier to interpret, while the positive ions spectrum is more evenly spread out over a large range of masses. Black bars represent peaks without chemical identification.

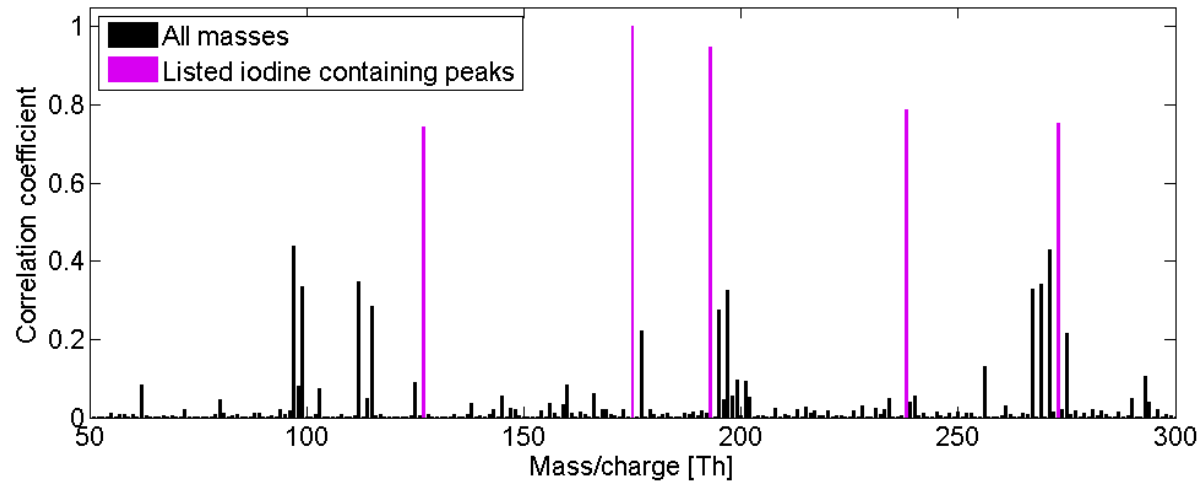

Fig. 11. Correlogram of integer $m / Q 175 \mathrm{Th}$ to peaks in the $m / Q$ range 50-300 Th. Correlation coefficients $\left(R^{2}\right)$ calculated for 7 days of ambient measurements. The highlighted iodine peaks refer to the iodine containing peaks in Fig. 10.

analysis, and the masses could easily be confirmed to contain iodine due to it's very negative mass defect. Iodine compounds can be abundant in ambient air, particularly in marine and coastal locations (O'Dowd et al., 2002). Negative ion chemical ionization of evaporated aerosol particles formed by photo-oxidation of iodine compounds produced mass spectra dominated by $m / Q 175\left(\mathrm{IO}_{3}^{-}\right)$in experiments by Hoffmann et al. (2001). However, the confirmation of the origin of the iodine ions will be left for further studies at the SMEAR III station.
The positive ion spectrum is spread out over many more ions than the negative. There are still two distinct groups that can be pointed out, and those are the alkyl amines and the alkyl pyridines. The pyridine series begins with pure protonated pyridine, followed by methyl pyridine, and continues with additions of $\left(\mathrm{CH}_{2}\right)_{n}$, with $n$ reaching at least 6 . With our instrument we are not able to distinguish between isomers, such as dimethyl pyridine or ethyl pyridine. The amine group follows the same pattern, going from the chemical formula of trimethyl to that of tributyl amine. These peaks still make up only a fraction of the total positive ions detected, and peak identification is still work in progress. 


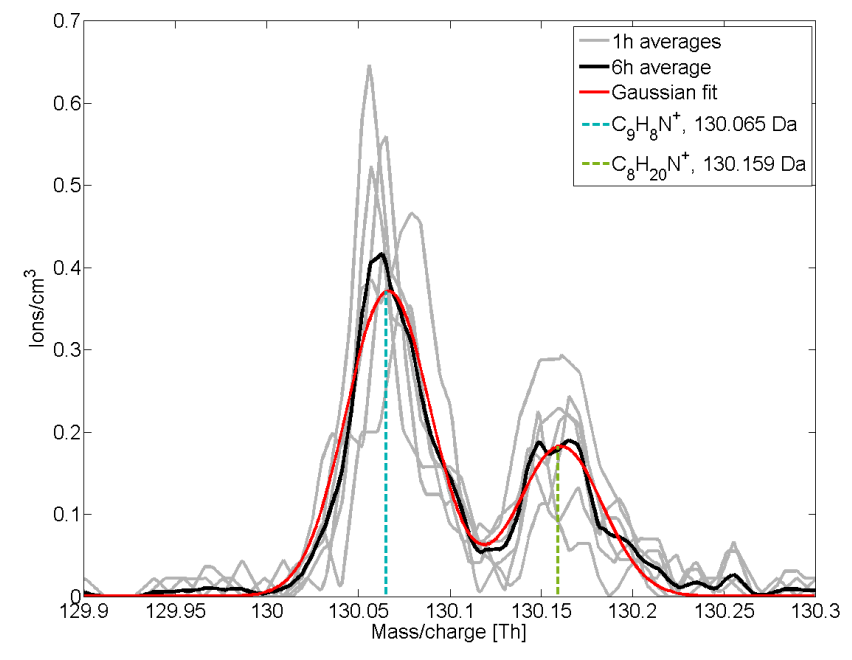

Fig. 12. High resolution spectrum of integer $m / Q 130 \mathrm{Th}$ in the positive ion spectrum, showing the clear separation between two peaks, most likely quinoline and an alkyl amine.

As an example of the mass resolving ability of the APiTOF, the positive ion mass spectrum at integer mass 130 is plotted in Fig. 12, for the same $6 \mathrm{~h}$ period as in Fig. 10. Also added to the figure are the $1 \mathrm{~h}$ averages, and a fit comprising of two gaussian modes to the $6 \mathrm{~h}$ average. The calculated masses for $\mathrm{C}_{9} \mathrm{H}_{8} \mathrm{~N}^{+}$and $\mathrm{C}_{8} \mathrm{H}_{20} \mathrm{~N}^{+}$are plotted as dashed lines. The first formula most likely corresponds to protonated quinoline, which has been detected already previously by Eisele (1989b) in the atmospheric ion population, whereas the second peak could be an alkyl amine, for instance dipropylethylamine.

Constraining the peak width according to Fig. 4, we can fit Gaussians to the entire data set and calculate the mass defects and corresponding Kendrick mass defects for each peak. The Kendrick diagram for the positive ions is plotted in Fig. 13. We can distinguish 6 different compound types instead of the two mentioned above. Four of these can be related to protonated amines (type $4 \mathrm{~N})$, protonated pyrrolines $(0 \mathrm{~N})$, protonated pyridines $(-4 \mathrm{~N})$ and protonated quinolines $(-10 \mathrm{~N})$, all with alkyl group additions. Many of these have been detected in the atmosphere previously (Eisele, 1986, 1989b). Clear homologues series are present also for types $-6 \mathrm{~N}$ and $-8 \mathrm{~N}$, but no chemical identification has yet been made.

\section{Conclusions}

In this paper we described the basic principles of the APiTOF, and tests peformed in the laboratory and in ambient conditions. The transmission of the APi-TOF was determined against an electrometer using mobility selected tetra alkyl ammonium halide ions. The transmission was 0.1$0.5 \%$ in the range $100-1300 \mathrm{Th}$, dropping off at both higher

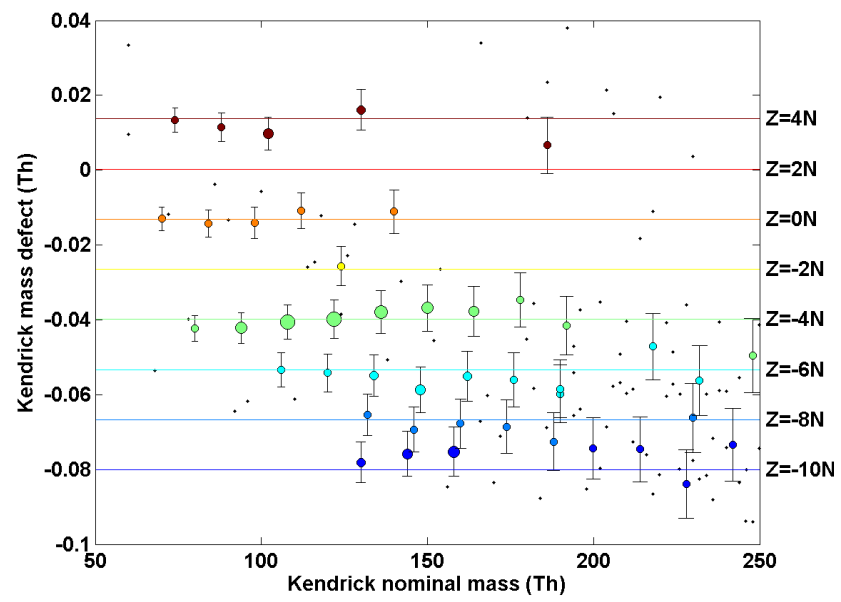

Fig. 13. Kendrick diagram of even $m / Q$ of positive ions converted to Kendrick mass scale. The same coloured circles represent peaks belonging to the same homologous series within $30 \mathrm{ppm}$ accuracy. The accuracy is mass dependent according to Fig. 4. Here only nitrogen containing compounds have been presented. Size of the coloured circles is scaled to the logarithm of signal strength.

and lower $m / Q$. It is sensitive to the voltage settings, and can be adjusted to maximise the transmission in a desired Th range.

The concentration response was tested with nebulised acridine, propanolol and verapamil. The APi-TOF featured a nearly linear response from $10^{7}$ to $10^{10}$ molec s$^{-1}$. At the high concentration, the deviation from a linear response is attributed to the fact that the bi-polar ion source was not able to produce enough ions to charge the sampled molecules.

Tests with a high concentration of nebulized sulphuric acid mixed with room air, revealed that sulphuric acid readily clusters with itself to form at least pentamers, but at higher $m / Q$ the ion spectrum was dominated by $\left(\mathrm{H}_{2} \mathrm{SO}_{4}\right)_{\mathrm{m}}\left(\mathrm{NH}_{3}\right)_{\mathrm{n}} \mathrm{HSO}_{4}^{-}$clusters.

During this study we developed tools to analyse time series of the mass spectra produced by the APi-TOF. The software package tofTools automatically performs the mass axis calibrations, and produces a high resolution mass spectral time series as well as integrated unit mass spectral time series. One major difference of this software compared to most other mass spectral analysis tools, is that it is optimized to produce high time resolution, mass calibrated spectra from data with very low signals. From the ambient measurements, we could determine the exact elemental composition of most abundant atmospheric ions up to $200 \mathrm{Th}$. Above this, we can still efficiently narrow down the possibilities, but the uncertainty increases as the number of possible molecules and the absolute mass uncertainty at each peak is higher, and a peak is more likely to be a combination of several overlaid peaks. Additonal techniques, such as Kendrick analysis and correlograms gave additional information in determining the compositions of several larger peaks as well. In the positive ion spectrum, 
6 different organic homologuous series were detected, the major ones being alkyl amines and alkyl pyridines. In the negative ion spectrum we detected mostly inorganic acids and their clusters.

The APi-TOF sampled naturally charged ions directly from ambient air without any chemical or electrical manipulation of the sample. It can also be coupled to external chargers and one of our future aims is to develop chemical ionization methods to be able to selectively detect also molecules and clusters that are not usually charged in the atmosphere. Recently Zhao et al. (2010) investigated the composition of neutral clusters using a cluster-CIMS. They used a quadrupole MS with unit mass resolving power coupled to a CI unit. By using $\mathrm{NO}_{3}^{-}$or $\mathrm{HNO}_{3} \cdot \mathrm{NO}_{3}^{-}$as a charger ion, they limit their studies to sulphuric acid and its clusters. By adding a chemical ionization unit to APi-TOF we can use weaker acids as charger ions and thus be less selective, but still able to interpret the mass spectra, due to the high mass accuracy and resolving power of the instrument.

The ultimate purpose of the APi-TOF is to sample molecules and clusters in ambient air, but also in laboratory and chamber studies. We have showed the instrument's ability to measure atmospherically relevant compounds such as charged $\left(\mathrm{H}_{2} \mathrm{SO}_{4}\right)_{\mathrm{m}}\left(\mathrm{NH}_{3}\right)_{\mathrm{n}} \mathrm{HSO}_{4}^{-}$clusters in the laboratory, and these clusters may play a very important role in aerosol particle formation. We also presented data of ambient naturally charged ions, which are typically present at concentrations below $1000 \mathrm{~cm}^{-3}$ per polarity. Regardless of the low concentrations, the APi-TOF provided clear mass spectra of the ions, and a large number of compounds were already identified. In ambient measurements the signals are often very low, and the high sensitivity, accuracy and resolution of the APi-TOF make it a very promising instrument for studies of nucleation and new particle formation.

Acknowledgements. This work has been partially funded by European Commission 6th Framework programme project EUCAARI, contract no 036833-2 (EUCAARI), by European Research Council project ATMNUCLE, by the Academy of Finland, Finnish Funding Agency for Technology and Innovation (Tekes) and the Graduate School of Chemical Sensors and Microanalytical Systems.

Edited by: A. Wiedensohler

\section{References}

Arnold, F.: Atmospheric ions and aerosol formation, Space Sci. Rev., 137, 225-239, 2008.

Arnold, F.: Multi-Ion complexes in the Stratosphere - implications for trace gases and aerosol, Nature, 284, 610-611, 1980.

Asmi, E., Sipilä, M., Manninen, H. E., Vanhanen, J., Lehtipalo, K., Gagné, S., Neitola, K., Mirme, A., Mirme, S., Tamm, E., Uin, J., Komsaare, K., Attoui, M., and Kulmala, M.: Results of the first air ion spectrometer calibration and intercomparison workshop, Atmos. Chem. Phys., 9, 141-154, doi:10.5194/acp-9-141-2009, 2009.
De Gouw, J. A. and Warneke, C.: Measurements of volatile organic compounds in the earth's atmosphere using proton-transferreaction mass spectrometry, Mass Spectrom. Rev., 26, 223-257, 2006.

DeCarlo, P. F., Kimmel, J. R., Trimborn, A., Northway, M. J., Jayne, J. T., Aiken, A. C., Gonin, M., Fuhrer, K., Horvath, T., Docherty, K. S., Worsnop, D. R., and Jimenez, J. L.: Fielddeployable, high-resolution, time-of-flight aerosol mass spectrometer, Anal. Chem., 78, 8281-8289, 2006.

Eisele, F. L.: Identification of tropospheric ions, J. Geophys. Res., 91, 7897-7906, 1986.

Eisele, F. L.: Natural and anthropogenic negative-ions in the troposphere, J. Geophys. Res.-Atmos., 94, 2183-2196, 1989a.

Eisele, F. L.: Natural and transmission-line produced positive-ions, J. Geophys. Res.-Atmos., 94, 6309-6318, 1989b.

Fernandez de la Mora, J., Thomson, B. A., and GameroCastano, M.: Tandem mobility mass spectrometry study of electrosprayed tetraheptyl ammonium bromide clusters, J. Am. Soc. Mass Spectr., 16, 717-732, 2005.

Guilhaus, M., Selby, D., and Mlynski, V.: Orthogonal acceleration time-of-flight mass spectrometry, Mass Spectrom Rev., 19, 65107,2000

Haapala, M., Luosujarvi, L., Saarela, V., Kotiaho, T., Ketola, R. A., Franssila, S., and Kostiainen, R.: Microchip for combining gas chromatography or capillary liquid chromatography with atmospheric pressure photoionization-mass spectrometry, Anal. Chem., 79, 4994-4999, 2007.

Hanson, D. R. and Eisele, F. L.: Measurement of prenucleation molecular clusters in the $\mathrm{NH}_{3}, \mathrm{H}_{2} \mathrm{SO}_{4}, \mathrm{H}_{2} \mathrm{O}$ system, J. Geophys. Res., 107, 4158, doi:10.1029/2001JD001100, 2002.

Harrison, R. G. and Tammet, H.: Ions in the terrestrial atmosphere and other solar system atmospheres, Space Sci. Rev., 137, 107118, 2008.

Herrmann, W., Eichler, T., Bernardo, N., and Fernandez de la Mora, J.: Turbulent transition arises at Re 35000 in a short Vienna type DMA with a large laminarizing inlet, Proceedings of the annual conference of the AAAR, St. Louis, MO, 6-10 October 2000 .

Hirsikko, A., Laakso, L., Hõrrak, U., Aalto, P. P., Kerminen, V.M., and Kulmala, M.: Annual and size dependent variation of growth rates and ion concentrations in boreal forest, Boreal Environ. Res., 10, 357-369, 2005.

Hoffmann, T., O’Dowd, C. D., and Seinfeld, J. H.: Iodine oxide homogeneous nucleation: an explanation for coastal new particle production, Geophys. Res. Lett., 28, 1949-1952, 2001.

Huey, L. G.: Measurement of trace atmospheric species by chemical ionization mass spectrometry: Speciation of reactive nitrogen and future directions, Mass. Spectrom. Rev., 26, 166-184, 2007.

Hughey, C. A., Hendrickson, C. L., Rodgers, R. P., Marshall, A. G., and Qian, K. N.: Kendrick mass defect spectrum: a compact visual analysis for ultrahigh-resolution broadband mass spectra, Anal. Chem., 73, 4676-4681, 2001.

Hussein, T., Dal Maso, M., Petaja, T., Koponen, I. K., Paatero, P., Aalto, P. P., Hameri, K., and Kulmala, M.: Evaluation of an automatic algorithm for fitting the particle number size distributions, Boreal Environ. Res., 10, 337-355, 2005.

Iida, K., Stolzenburg, M. R., McMurry, P. H., and Smith, J. N.: Estimating nanoparticle growth rates from size-dependent charged fractions: Analysis of new particle formation events 
in Mexico City, J. Geophys. Res.-Atmos., 113, D05207, doi:10.1029/2007JD009260, 2008.

Jaitly, N., Monroe, M. E., Petyuk, V. A., Clauss, T. R. W., Adkins, J. N., and Smith, R. D.: Robust algorithm for alignment of liquid chromatography-mass spectrometry analyses in an accurate mass and time tag data analysis pipeline, Anal. Chem., 78, 7397-7409, 2006.

Järvi, L., Hannuniemi, H., Hussein, T., Junninen, H., Aalto, P. P., Hillamo, R., Makela, T., Keronen, P., Siivola, E., Vesala, T., and Kulmala, M.: The urban measurement station SMEAR III: Continuous monitoring of air pollution and surface-atmosphere interactions in Helsinki, Finland, Boreal Environ. Res., 14, 86-109, 2009.

Jayne, J. T., Leard, D. C., Zhang, X. F., Davidovits, P., Smith, K. A., Kolb, C. E., and Worsnop, D. R.: Development of an aerosol mass spectrometer for size and composition analysis of submicron particles, Aerosol Sci. Technol., 33, 49-70, 2000.

Jimenez, J. L., Canagaratna, M. R., Donahue, N. M., Prevot, N. M., Zhang, Q., Kroll, J. H., DeCarlo, P. F., Allan, J. D., Coe, H., Ng, N. L., Aiken, A. C., Docherty, K. S., Ulbrich, I. M., Grieshop, A. P., Robinson, A. L., Duplissy, J., Smith, J. D., Wilson, K. R., Lanz, V. A., Hueglin, C., Sun, Y. L., Tian, J., Laaksonen, A., Raatikainen, T., Rautiainen, J., Vaattovaara, P., Ehn, M., Kulmala, M., Tomlinson, J. M., Collins, D. R., Cubison, M. J., Dunlea, E. J., Huffman, J. A., Onasch, T. B., Alfarra, M. R., Williams, P. I., Bower, K., Kondo, Y., Schneider, J., Drewnick, F., Borrmann, S., Weimer, S., Demerjian, K., Salcedo, D., Cottrell, L., Griffin, R., Takami, A., Miyoshi, T., Hatakeyama, S., Shimono, A., Sun, J. Y., Zhang, Y. M., Dzepina, K., Kimmel, J. R., Sueper, D., Jayne, J. T., Herndon, S. C., Trimborn, A. M., Williams, L. R., Wood, E. C., Middlebrook, A. M., Kolb, C. E., Baltensperger, U., and Worsnop, D. R.: Evolution of Organic Aerosols in the Atmosphere, Science, 326, 1525-1529, 2009.

Jordan, A., Haidacher, S., Hanel, G., Hartungen, E., Mark, L., Seehauser, H., Schottkowsky, R., Sulzer, P., and Mark, T. D.: A high resolution and high sensitivity proton-transfer-reaction time-offlight mass spectrometer (PTR-TOF-MS), Int. J. Mass. Spectrom., 286, 122-128, 2009.

Kendrick, E.: A mass scale based on $\mathrm{CH}_{2}=14.0000$ for high resolution mass spectrometry of organic compounds, Anal. Chem., 35, 2146-2154, 1963.

Kerminen, V.-M., Pirjola, L., and Kulmala, M.: How signifigantly does coagulation scavening limit atmospheric particle production?, J. Geophys. Res., 106, 24119-24125, 2001.

$\mathrm{Ku}, \mathrm{B}$. K. and Fernandez de la Mora, J.: Relation between electrical mobility, mass, and size for nanodrops $1-6.5 \mathrm{~nm}$ in diameter in air, Aerosol Sci. Technol., 43, 241-249, 2009.

Kulmala, M. and Kerminen, V. M.: On the formation and growth of atmospheric nanoparticles, Atmos. Res., 90, 132-150, 2008.

Kulmala, M., Riipinen, I., Sipila, M., Manninen, H. E., Petaja, T., Junninen, H., Dal Maso, M., Mordas, G., Mirme, A., Vana, M., Hirsikko, A., Laakso, L., Harrison, R. M., Hanson, I., Leung, C., Lehtinen, K. E. J., and Kerminen, V. M.: Toward direct measurement of atmospheric nucleation, Science, 318, 89-92, 2007.

Kulmala, M., Vehkamaki, H., Petaja, T., Dal Maso, M., Lauri, A., Kerminen, V. M., Birmili, W., and McMurry, P. H.: Formation and growth rates of ultrafine atmospheric particles: a review of observations, J. Aerosol Sci., 35, 143-176, 2004.
Kulmala, M.: How particles nucleate and grow, Science, 302, 10001001, 2003.

Marquardt, D. W.: An algorithm for least-squares estimation of nonlinear parameters, J. Soc. Ind. Appl. Math., 11, 431-441, 1963.

Martinez-Lozano, P. and de la Mora, J. F.: On-line detection of human skin vapors, J. Am. Soc. Mass. Spectr., 20, 1060-1063, 2009.

Mirme, A., Tamm, E., Mordas, G., Vana, M., Uin, J., Mirme, S., Bernotas, T., Laakso, L., Hirsikko, A. and Kulmala, M.: A widerange multi-channel air ion spectrometer, Boreal Environ. Res., 12, 247-264, 2007.

O’Dowd, C. D., Jimenez, J. L., Bahreini, R., Flagan, R. C., Seinfeld, J. H., Hameri, K., Pirjola, L., Kulmala, M., Jennings, S. G., and Hoffmann, T.: Marine aerosol formation from biogenic iodine emissions, Nature, 417, 632-636, 2002.

Ortega, I. K., Kurtén, T., Vehkamäki, H., and Kulmala, M.: Corrigendum to "The role of ammonia in sulfuric acid ion induced nucleation" published in Atmos. Chem. Phys., 8, 2859-2867, 2008, Atmos. Chem. Phys., 9, 7431-7434, doi:10.5194/acp-97431-2009, 2009.

Östman, P., Marttila, S. J., Kotiaho, T., Franssila, S., and Kostiainen, R.: Microchip atmospheric pressure chemical ionization source for mass spectrometry, Anal. Chem., 76, 6659-6664, 2004.

Saarela, V., Haapala, M., Kostiainen, R., Kotiaho, T., and Franssila, S.: Glass microfabricated nebulizer chip for mass spectrometry, Lab Chip, 7, 644-646, 2007.

Sipila, M., Lehtipalo, K., Attoui, M., Neitola, K., Petaja, T., Aalto, P. P., O'Dowd, C. D., and Kulmala, M.: Laboratory verification of PH-CPC's ability to monitor atmospheric sub-3 nm clusters, Aerosol Sci. Technol., 43, 126-135, 2009.

Sipilä, M., Lehtipalo, K., Kulmala, M., Petäjä, T., Junninen, H., Aalto, P. P., Manninen, H. E., Kyrö, E.-M., Asmi, E., Riipinen, I., Curtius, J., Kürten, A., Borrmann, S., and O'Dowd, C. D.: Applicability of condensation particle counters to measure atmospheric clusters, Atmos. Chem. Phys., 8, 4049-4060, doi:10.5194/acp-8-4049-2008, 2008.

Smith, J. N., Dunn, M. J., Vanreken, T. M., Iida, K., Stolzenburg, M. R., McMurry, P. H., and Huey, L. G.: Chemical composition of atmospheric nanoparticles formed from nucleation in Tecamac, Mexico: Evidence for an important role for organic species in nanoparticle growth, Geophys. Res. Lett., 35, L04808, doi:10.1029/2007GL032523, 2008.

Smith, J. N., Moore, K. F., Eisele, F. L., Voisin, D., Ghimire, A. K., Sakurai, H., and McMurry, P. H.: Chemical composition of atmospheric nanoparticles during nucleation events in Atlanta, J. Geophys. Res., 110, D22S03, doi:10.1029/2005JD005912, 2005.

Smith, J. S., Laskin, A., and Laskin, J.: Molecular characterization of biomass burning aerosols using high-resolution mass spectrometry, Anal. Chem., 81, 1512-1521, 2009.

Tanner, D. J. and Eisele, F. L.: Ions in oceanic and continental air masses, J. Geophys. Res.-Atmos., 96, 1023-1031, 1991.

Ude, S. and Fernandez de la Mora, J. F.: Molecular monodisperse mobility and mass standards from electrosprays of tetra-alkyl ammonium halides, J. Aerosol. Sci., 36, 1224-1237, 2005.

Voisin, D., Smith, J. N., Sakurai, H., McMurry, P. H., and Eisele, F. L.: Thermal desorption chemical ionization mass spectrometer for ultrafine particle chemical composition, Aerosol Sci. 
Technol., 37, 471-475, 2003.

Vorm, O. and Mann, M.: Improved Mass Accuracy in MatrixAssisted Laser Desorption/Ionization Timeof- Flight MassSpectrometry of Peptides, J. Am. Soc. Mass. Spectr., 5, 955-958, 1994.

Wolski, W. E., Lalowski, M., Jungblut, P., and Reinert, K.: Calibration of mass spectrometric peptide mass fingerprint data without specific external or internal calibrants, BMC Bioinformatics, 6 , 203, doi:10.1186/1471-2105-6-203, 2005.
Zhao, J., Eisele, F. L., Titcombe, M., Kuang, C., and McMurry, P. H.: Chemical ionization mass spectrometric measurements of atmospheric neutral clusters using the cluster-CIMS, J. Geophys. Res., 115, D08205, doi:10.1029/2009JD012606, 2010. 